\title{
Biological characteristics of methicillin resistant Staphylococcus aureus strains isolated from hospitals in Colombo
}

Nelun de Silva' and Lalitha Mendis ${ }^{2}$

The Ceylon Journal of Medical Science 1996; 39: 61-67

\section{Summary}

This study was done to determine the antibiogram and biological characteristics of Methicillin resistant Staphylococcus aureus (MRSA) clinical jsolates, to detect the existence of a multi-resistant strain conforming to an epidemic MRSA strain.

Specimens received from some wards of the General Hospital Colombo, and other hospitals in Colombo and from a few out patients, during a fourteen month period, yielded sixty five MRSA strains.

These strains were characterized by the following tests:

Antibiotic susceptibility tests, coagulase production with human and rabbit plasma, urea hydrolysis at 24 and 48 hours, protein A levels, and pigment production.

Forty five MRSA strains were resistant to the same seven antibiotics in addition to methicillin, and were arbitrarily named group $A$. This was the predominant strain in the surgical units (SU), plastic surgery unit (PSU) and burns unit (BU).

Ninety seven percent of MRSA were resistant to at least one aminoglycoside tested. Resistance to fusidic acid $(8 \%)$, clindamicin $(8 \%)$ and rifampicin (4.6\%) was rare in MRSA's. All MRSA strains tested were sensitive to vancomycin.

The multi-resistant strain - group A, differed from the miscellaneous strains (group $B$ ) in the following way; they were marginally stronger in the coagulase test than group $B$, urea hydrolysis was greater at 24 and 48 hours ( $P=0.0125$ and
$P=0.0165)$, protein A levels were marginally higher and the strains were more pigmented. Protein A levels were however low in all the MRSA's when compared to the Cowan strain of $S$. aureus. The multi-resistant, group A strain to some extent showed the biological characteristics of an epidemic strain of MRSA (EMRSA) described in the literature, which have spread among hospitalised patients and caused serious outbreaks of hospital infections. It remains to be seen if this strain too, will be the likely cause of outbreaks of serious hospital infections in Colombo, as has been described elsewhere in the world.

\section{Introduction}

Staphylococcus aureus is a versatile human pathogen that has been the focus of clinicians, microbiologists and research scientists throughout the globe. In recent years there has been a marked increase in the number of hospital infections caused by resistant strains of S. aureus, especially MRSA. Many reports from Europe, Australia, United Kingdom, United States and South Africa have shown that these strains spread easily and are difficult to control (1).

Several surveys of MRSA have used varying combinations of techniques to characterize and identify MRSA strains and also to identify epidemic MRSA strains. These include combinations of antibiotic susceptibility patterns, phage typing and biochemical tests.

A survey of MRSA, affecting patients in England and Wales analyzed 660 isolates for a six month period, using phage typing, antibiotic susceptibility and selected biochemical tests such as protein A production, urea hydrolysis and clumping factor production (2). 
This study was undertaken to characterize methicillin resistant strains of $S$. aureus isolated in selected wards and specialized units of some hospitals in Colombo in order to detect the existence and prevalence of EMRSA strains within the hospital environment.

\section{Materials and Methods}

Sixty five strains of MRSA were isolated (3) from specimens processed in the laboratory of the Department of Microbiology, Faculty of Medicine, Colombo, during a fourteen month period. The specimens were received from two surgical wards (SU), plastic surgery unit (PSU), premature baby unit (PBU), burns unit (BU) and from a miscellaneous group (MG) comprising a paediatric ward, medical wards of the hospitals in Colombo and a few out patients.

\section{Characterization Tests:}

1. Antibiogram

2. Clumping factor (coagulase) production

3. Urea hydrolysis

4. Protein A production

5. Pigment on milk agar

Antibiogram (modified Kirby-Bauer method):

Fourteen antibiotics in the following concentrations were tested against the MRSA strains: (Neo sensitabs - Rosco diagnostics):

$\begin{array}{lllr}\text { oxacillin } & 1 \mu \mathrm{g} & \text { ofloxacin } & 10 \mu \mathrm{g} \\ \text { netilmicin } & 10 \mu \mathrm{g} & \text { fusidic acid } & 400 \mu \mathrm{g} \\ \text { vancomycin } & 70 \mu \mathrm{g} & \text { erythromycin } 78 \mu \mathrm{g} \\ \text { gentamicin } & 40 \mu \mathrm{g} & \text { rifampin } & 30 \mu \mathrm{g} \\ \text { tetracycline } & 80 \mu \mathrm{g} & \text { penicillin } & 5 \mu \mathrm{g} \\ \text { chloramphenicol } & 60 \mu \mathrm{g} & \text { clindamycin } & 25 \mu \mathrm{g} \\ \text { cefotaxime } & 30 \mu \mathrm{g} & \text { tobramycin } & 40 \mu \mathrm{g}\end{array}$

\section{Clumping factor (coagulase) production:}

The test was performed using undiluted rabbit and human plasma. Colonies from an overnight culture on nutrient agar were emulsified in sterile saline, checked for auto agglutination and plasma added with a straight wire. Ten seconds were allowed for mixing, followed by 20 seconds of rotation, before the final reading. To quantify results for interpretation of the reaction, an arbitrary scoring system was followed (4):

$4+, 3+, 2+$ and $1+$

negative - no agglutination or clearing.

Urea hydrolysis:

Standard Christensen urea slopes were stab inoculated with the bacterial strains and incubated at $37 \mathrm{C}$.

Readings were made at 24 and 48 hours and quantified on an arbitrary scale, depending on the intensity of colour produced, and determined visually. The maximum possible colour was given a score of 4 and no colour change, a score of 0 (2).

\section{Protein A titres:}

A method for quantifying of cell bound protein A of $S$. aureus by means of a haemagglutination technique, with sheep erythrocytes differentially sensitized with rabbit anti sheep anti serum (Amboceptor-Behring Ltd.) was used on all MRSA strains (5).

The Cowan strain which is known to be a good protein A producer was used as a positive control (5). The titer of protein A was expressed as $2^{(n-1)}$ where $n=$ well number showing haemagglutination.

Pigment production on milk agar:

Strains of MRSA were inoculated in the form of streaks on the surface of milk agar and incubated for 24 hours at $37^{\circ} \mathrm{C}$ followed by, overnight incubation at room temperature to enhance pigment production. Depending on the intensity of the colour produced the terms orange, yellow and cream were used to categorize pigment production of MRSA strains.

\section{Computing methods:}

The data collected in the study was analyzed using DBase 111 plus (Ashton Tate) programme. 
Results

\section{Antibiogram:}

Sixty three of 65 strains (97\%) of MRSA were resistant to at least one aminoglycoside and could be categorized as Methicillin Aminoglycoside resistant $S$. aureus (MARSA). Of these, 60 strains were resistant to two aminoglycosides and 3 strains were resistant to all three aminoglycosides tested.

Ofloxacin resistance was variable. Twenty one strains were resistant $(32 \%)$. Intermediate resistance was seen in 6 strains.

The majority of MRSA strains were sensitive to fusidic acid $(92 \%)$, clindamycin $(92 \%)$ and rifampicin (95.4\%) and netilmicin (95\%). All 5 strains resistant to fusidic acid were isolates from the burns unit. All 65 strains were sensitive to vancomycin. Percentage of resistance of MRSA strains to the 14 antibiotics tested are shown in Figure 1.

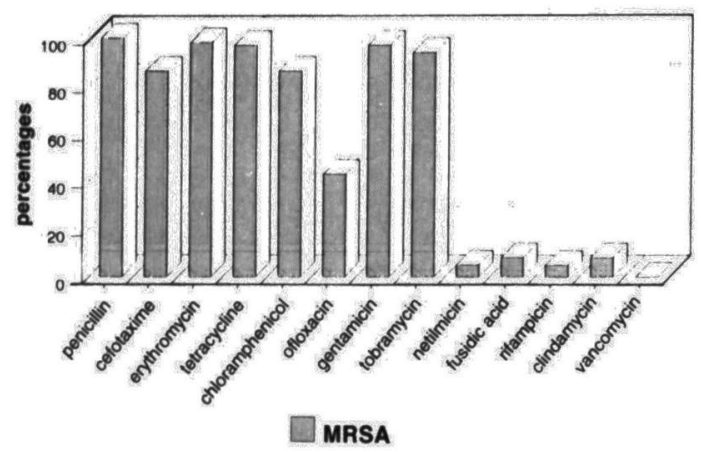

Fig. 1 Percentage of resistance of MRSA to antibiotics tested

Thirty two percent and $46 \%$ of the MRSA strains were resistant to 8 and 9 antibiotics respectively. A uniformity in the antibiotic susceptibility pattern of the MRSA strains was seen. Forty five strains showed resistance to the same 7 antibiotics in addition to methicillin. The antibiotics were gentamicin, tetracycline, chloramphenicol, cefotaxime, erythromycin, penicillin and tobramycin. These 45 strains were designated group $\mathrm{A}$. The remaining 20 miscellaneous strains that showed resistance to less than 8 antibiotics were designated group B. The distribution of the multiple antibiotic resistant strain of MRSA (group A) and of the miscellaneous group (group B) in the different wards is shown in Figure 2.

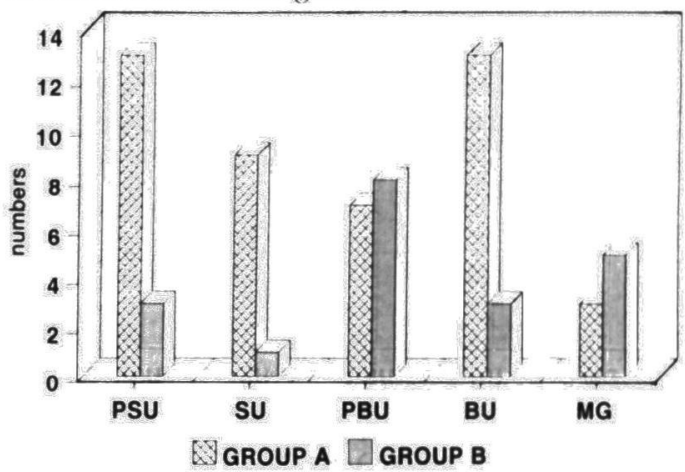

Fig. 2 Distribution of groups $A$ and $B$ of MRSA

PSU - plastic surgery unit, SU-surgical units PBU - premature baby unit, BU-burns unit MG - miscellaneous group

Of the total 10 MRSA strains in the general surgical ward, 9 were of the multiple antibiotic resistant strain type (Group $A$ ). In the specialized units too, the predominant strain type was group $A$. The premature baby unit had nearly equal numbers of group $A$ and $B$ strains. The miscellaneous group showed a predominance of group B type.

Clumping factor (coagulase) production:

Table 1.1. Comparison of coagulase production of group A and B of MRSA (human plasma)

\begin{tabular}{|cccc|}
\hline $\begin{array}{c}\text { Coagulase } \\
\text { scores }\end{array}$ & Group A & Group B & Total \\
\hline $4+$ & 28 & 9 & 37 \\
$3+$ & 11 & 5 & 16 \\
$2+$ & 5 & 1 & 6 \\
$1+$ & 1 & 4 & 5 \\
0 & - & 1 & 1 \\
\hline Total & 45 & 20 & 65 \\
\hline
\end{tabular}


Table 1.2. Comparison of coagulase production of group A and B of MRSA (rabbit plasma)

\begin{tabular}{|cccc|}
\hline $\begin{array}{c}\text { Coagulase } \\
\text { scores }\end{array}$ & Group A & Group B & Total \\
\hline $4+$ & 13 & 5 & 18 \\
$3+$ & 15 & 3 & 18 \\
$2+$ & 10 & 5 & 15 \\
$1+$ & 6 & 5 & 11 \\
0 & 1 & 2 & 3 \\
\hline Total & 45 & 20 & 65 \\
\hline
\end{tabular}

Group A scores were marginally higher than group B scores when both human and rabbit plasma were used. Differences were not statistically significant.

\section{Urea hydrolysis:}

Table 2.1. Comparison of urea hydrolysis at 24 hr of group A and B of MRSA

\begin{tabular}{|rccc|}
\hline $\begin{array}{l}\text { Urea } \\
\text { scores }\end{array}$ & Group A & Group B & Total \\
\hline 3 & 11 & 2 & 13 \\
2 & 20 & 7 & 27 \\
1 & 10 & 3 & 12 \\
0 & 9 & 8 & 13 \\
\hline Total & 45 & 20 & 65 \\
\hline
\end{tabular}

Table 2.2. Comparison of urea hydrolysis at 48 hr of group. A and B of MRSA

\begin{tabular}{|rccc|}
\hline $\begin{array}{l}\text { Urea } \\
\text { scores }\end{array}$ & Group A & Group B & Total \\
\hline & 1 & 1 & 2 \\
4 & 22 & 3 & 25 \\
3 & 17 & 9 & 26 \\
2 & 2 & 1 & 3 \\
1 & 3 & 6 & 9 \\
0 & 45 & 20 & 65 \\
\hline Total & & & \\
\hline
\end{tabular}

Urea hydrolysis was significantly greater in group $A$ than in group $B$ at 24 and 48 hours. $(\mathrm{P}=0.0215$ and $\mathrm{P}=0.0165$ respectively).

\section{Protein A titres:}

Table 3. Comparison of protein A production of group A and B of MRSA

\begin{tabular}{|lccc|}
\hline $\begin{array}{c}\text { Protein A } \\
\text { Titres }\end{array}$ & Group A & Group B & Total \\
\hline$<32$ & 42 & 18 & 601 \\
$>=32$ & 3 & 2 & 5 \\
\hline Total & 45 & 20 & 65 \\
\hline
\end{tabular}

Protein A levels of group A was higher than in group $B$ but the differences were not significant.

\section{Pigment Production}

Group A strains were more pigmented than group B MRSA strains, but here too the differences were not significant statistically. (Table 4).

Table 4. Comparison of pigment production of group $A$ and $B$ of MRSA

\begin{tabular}{|lccc|}
\hline Pigment & Group A & Group B & Total \\
\hline Cream & 15 & 14 & 29 \\
Yellow & 25 & 5 & 30 \\
Orange & 5 & 1 & 6 \\
\hline Total & 45 & 20 & 65 \\
\hline
\end{tabular}

The results of the biochemical tests of the 2 groups of MRSA (A and B) were compared statistically using the Mann - Whitney U test.

\section{Discussion}

In the last two decades a rapid increase in the number of Methicillin Resistant Staphylococcus aureus (MRSA) isolated from hospitalized patients, was reported in many parts of the 
world. In most cases intensive care units, burns units, surgical and neonatal wards have been the source of these isolations initially $(6,7)$.

Forty five of 65 MRSA strains (group A) in the present study had a similar antibiogram and were resistant to the same eight antibiotics. The probability that these 45 strains are a single strain type is based on the comparison of the biochemical test results. Group A strains, in some respects, differed significantly from the miscellaneous strains (group B). Urea hydrolysis at 24 and 48 hours was significantly greater in group A strains than group B strains. Group A strains also produced greater amounts of coagulase and pigment than the other strains. Protein A production was marginally greater in group A than in group B but the titers were low when compared to the Cowan strain of $S$. aureus.
Reports of protein A levels of MRSA in comparison with standard strains producing high levels of protein $A$ are not consistant, eg. some authors $(8,9)$ reported MRSA producing low levels while others have reported MRSA producing significantly greater amounts of protein A (10).

Comparison of protein A levels between MRSA strains has shown that strains defined as epidemic MRSA (EMRSA) produced low levels of protein $A$ when compared to other MRSAs (10). In the present study protein A levels of group A strains did not differ significantly from group B strains.

Orange pigment production has been shown to be a uniform trait in some of the British isolates but has not been so in other hospital strains (11).

Table 5. Comparison of antibiogram and biological characters of EMRSA

\begin{tabular}{|c|c|c|c|c|c|}
\hline & $\begin{array}{l}\text { Marplẹs } \\
\text { et al } 1986\end{array}$ & $\begin{array}{c}\text { Roberts } \\
\text { \& Gaston } \\
1987\end{array}$ & $\begin{array}{l}\text { Cookson } \\
\text { et al } 1988\end{array}$ & $\begin{array}{c}\text { Kerr } \\
\text { et al } 1990\end{array}$ & $\begin{array}{c}\text { this study } \\
1993\end{array}$ \\
\hline $\begin{array}{l}\text { Antibiogram } \\
\text { (resistant to) }\end{array}$ & $\begin{array}{c}T / M n / S / \\
G / C / E\end{array}$ & NT & $\begin{array}{c}\mathrm{T} / \mathrm{Mn} / \mathrm{S} / \\
\mathrm{C} / \mathrm{TS} / \mathrm{E} \\
\text { rarely } \\
\mathrm{F} / \mathrm{R} / \mathrm{N}\end{array}$ & $\begin{array}{c}\mathrm{P} / \mathrm{T} / \mathrm{E} \\
\mathrm{K} / \mathrm{G} / \mathrm{S} \\
\mathrm{Mn} / \mathrm{To} / \mathrm{L} \\
\text { rarely } \mathrm{F}\end{array}$ & $\begin{array}{c}\mathrm{P} / \mathrm{T} / \mathrm{E} \\
\mathrm{G} / \mathrm{To} / \mathrm{C} \\
\text { rarely } \\
\mathrm{F} / \mathrm{R} / \mathrm{CL}\end{array}$ \\
\hline $\begin{array}{l}\text { Clumping } \\
\text { factor }\end{array}$ & NT & $\begin{array}{c}\text { strongly+ } \\
\text { OMRSA- } \\
\text { weakly+ }\end{array}$ & NT & + & $>$ grp. B \\
\hline $\begin{array}{l}\text { Urea } \\
\text { hydrolysis }\end{array}$ & NT & NT & NT & + & >grp. B \\
\hline \multirow[t]{2}{*}{$\begin{array}{l}\text { Protein A } \\
\text { levels }\end{array}$} & NT & $\begin{array}{c}\text { low; lower } \\
\text { than OMRSA }\end{array}$ & NT & $\begin{array}{l}\text { low; lower } \\
\text { than OMRSA }\end{array}$ & $\begin{array}{l}\text { low; marginally } \\
\text { higher than }\end{array}$ \\
\hline & & & & & OMRSA \\
\hline$P=$ penicillin & & \multicolumn{3}{|l|}{ To=tobramycin } & \\
\hline$T=t e t r a c y c l i n e$ & & \multicolumn{2}{|c|}{$E=e r y$ thromycin } & & \\
\hline Mn=minocycline & & \multicolumn{2}{|c|}{$\mathrm{C}=$ chloramphenicol } & & \\
\hline S=streptomycin & & \multicolumn{3}{|c|}{ TS=trimethoprim/sulphamethoxazole } & \\
\hline $\mathrm{G}=$ gentamicin & & \multicolumn{2}{|c|}{ F=fusidic acid } & & \\
\hline K=kanamycin & & \multicolumn{2}{|l|}{ R=rifampicin } & & \\
\hline $\mathrm{Cl}=\mathrm{clindamycin}$ & & \multicolumn{2}{|l|}{$\mathrm{N}=$ neomycin } & & \\
\hline EMRSA =epidemic MRS & & \multicolumn{2}{|c|}{ OMRSA $=$ other MRSA } & NT= not tested & \\
\hline
\end{tabular}

Vol. 39 No. 2, December 1996 
Orange pigmentation was not a characteristic among our MRSA isolates. Most of the biochemical characteristics of MRSA examined have been at varying times linked to virulence of the organism (12). Other studies have reported that MRSA and methicillin sensitive $S$. aureus (MSSA) are of equal pathogenecity when biological characteristics are compared (9). The existence of an epidemic strain of MRSA (EMRSA) with specific phage patterns, biochemical characteristics and immunological features has been reported $(12,13,14)$.

In a study by Kerr et al (2) antibiotic resistant patterns were not clear markers of EMRSA except that multi resistance was common in epidemic strains. EMRSA was strongly clumping factor positive and ammonia was produced from urea. However they produced low levels of protein A. Other MRSAs isolated in hospitals were not uniform in these tests. The group A MRSA strains in the present study conforms to some extent with an epidemic strain of MRSA described in the literature $(14,10,2)$. (Table 5)

Group A strains were more prevalent in the surgical wards and burns unit and group B strains predominated in the premature baby unit and the miscellaneous settings. It may be that patients with post operative wounds and burns are colonized with this 'epidemic strain' (group A) during their prolonged hospital stay.

Outbreaks of infections with MRSA were not reported during the period of study in any of the wards and units screened. Except for some isolations of MRSA from blood cultures and swabs from sterile sites, the significance of isolation of MRSA from post operative wound infections and burns could not be determined since close follow up of these patients was not feasible. Therefore the extent of the problem of MRSA being the cause of serious infections in the hospital could not be determined at this point of time.

However, the potential of the multi-resistant (group A) MRSA strains being the cause of outbreaks of hospital infections is a reality and infection control teams need to be vigilant in this respect.

\section{Acknowledgements}

The authors are grateful for the financial assistance provided by the Health Systems Research Programme of the National Institute of Health Sciences, Kalutara.

The technical assistance of Ms. Chitra Ranjithan, the secretarial help of Ms. Shirani Hendalage and the co-operation of the staff of Microbiology Department, Faculty of Medicine, Colombo, is deeply appreciated. The assistance given by the staff of the respective wards and by the consultant surgeon of the burns unit in the National Hospital is acknowledged.

\section{References}

1. Report of a Combined Working Party of the Hospital Infection Society and British Society for Antimicrobial Chemotherapy. Guidelines for the control of epidemic methicillin resistant Staphylococcus aureus. Journal of Hospital Infection 1986; 7: 193-201.

2. Kerr S, Kerr GE, Mackintosh CA. Marples RR. A survey of methicillin-resistant $S$ aureus affecting patients in England and Wales. Journal of Hospital Infection 1990; 16: 35-48.

3. Kloos WE, Lambe DW. Manuel of Clinical Microbiology. 5th edition. American Socjety for Microbiology, Washington DC 1991. p. 226-233.

4. Dickson J., Marples RR. Coagulase production by strains of $S$. aureus of differing resistance characters: a comparison of two traditional methods with a latex agglutination system detecting both clumping factor and protein A. Journal of Clinical Pathology 1986; 39: 371-375.

5. Hwang SM. Seki K, Mural M, Sakurada J, Nishihara S, Mareda T, Masuda S. Simple 
method for quantitation of cell bound Protein A on Staphylococcus aureus by means of haemagglutination with sheep erythrocytes differentially sensitized with rabbit antibody and its clinical application. Microbiology and Immunology 1989; 33: 155-163.

6. Perera K, Gunawathie C, Rajamanthri A, Atukorala SD. Methicillin Resistant Staphylococcus aureus (MRSA). Journal of the Ceylon College of Physicians 1991; 24: 47-49.

7. Thompson RL, Cabezudo I, Wenzel RP. Epidemiology of nosocomial infections caused by methicillin resistant Staphylococcus aureus. Annals of Internal Medicine 1982; 97: 309-317.

8. Winbald S, Ericsson C. Sensitized sheep red cells as a reactant for Staphylococcus aureus protein A. Acta Pathologia Microbiologia Scandinavia (B) 1973; 81: 150-156.

9. Jacob JE. Characterization of a strain of Methicillin and aminoglycoside resistant Staphylococcus aureus endemic in the
National University Hospital, Singapore. (Thesis) National University of Singapore 1991.

10. Roberts J, Gaston MA. Protein A and coagulase expression in epidemic and non epidemic $S$. aureus. Journal of Clinical Pathology 1987; 40: 837-840.

11. Grieble HG, Krause SL, Pappas SA, Dicostanzo MB. The prevalence of high level methicillin resistant hospital staphylococci. Medicine 1981; 60: 62-69.

12. Lacey RW, Stokes A. Studies on recently isolated cultures of methicillin resistant Staphylococcus aureus Journal of General Microbiology 1979; 114: 329-339.

13. Marples RR, Richardson JF, de Saxe MJ. Bacteriological characters of strains of $S$. aureus submitted to a reference laboratory related to methicillin resistance. Journal of Hygiene 1986; 96: 217-223.

14. Cookson B, Phillips I. Journal of Applied Bacteriology, symposium supplement 1990; $55 S-70 S$. 